\title{
Response of the East Asian climate system to water and heat changes of global frozen soil using NCAR CAM model
}

\author{
XIN YuFei ${ }^{1,2}$, WU Bing Yi ${ }^{1 *}$, BIAN LinGen ${ }^{1}$, LIU Ge $^{1},{\text { ZHANG } \text { Lin }^{2} \& \text { LI Ren }}^{3}$ \\ ${ }^{1}$ Chinese Academy of Meteorological Sciences, Beijing 100081, China; \\ ${ }^{2}$ Nanjing University of Information Science and Technology, Nanjing 210044, China; \\ ${ }^{3}$ Cold and Arid Regions Environmental and Engineering Research Institute, Lanzhou 730000, China
}

Received March 5, 2012; accepted May 30, 2012; published online July 26, 2012

\begin{abstract}
Under the condition of land-atmosphere heat and water conservation, a set of sensitive numerical experiments are set up to investigate the response of the East Asian climate system to global frozen soil change. This is done by introducing the supercooled soil water process into the Community Land Model (CLM3.0), which has been coupled to the National Center of Atmospheric Research Community Atmosphere Model (CAM3.1). Results show that: (1) The ratio between soil ice and soil water in CLM3.0 is clearly changed by the supercooled soil water process. Ground surface temperature and soil temperature are also affected. (2) The Eurasian (including East Asian) climate system is sensitive to changes of heat and water in frozen soil regions. In January, the Aleutian low sea level pressure circulation is strengthened, Ural blocking high at $500 \mathrm{hPa}$ weakened, and East Asian trough weakened. In July, sea level pressure over the Aleutian Islands region is significantly reduced; there are negative anomalies of 500 $\mathrm{hPa}$ geopotential height over the East Asian mainland, and positive anomalies over the East Asian ocean. (3) In January, the southerly component of the $850 \mathrm{hPa}$ wind field over East Asia increases, indicating a weakened winter monsoon. In July, cyclonic anomalies appear on the East Asian mainland while there are anticyclonic anomalies over the ocean, reflective of a strengthened east coast summer monsoon. (4) Summer rainfall in East Asia changed significantly, including substantial precipitation increase on the southern Qinghai-Tibet Plateau, central Yangtze River Basin, and northeast China. Summer rainfall significantly decreased in south China and Hainan Island, but slightly decreased in central and north China. Further analysis showed considerable upper air motion along $\sim 30^{\circ} \mathrm{N}$ latitude, with substantial descent of air at its north and south sides. Warm and humid air from the Northeast Pacific converged with cold air from northern land areas, representing the main cause of the precipitation anomalies.
\end{abstract}

frozen soil, supercooled soil water, GCMs, East Asian monsoon, summer rainfall anomalies

Citation: $\quad$ Xin Y F, Wu B Y, Bian L G, et al. Response of the East Asian climate system to water and heat changes of global frozen soil using NCAR CAM model. Chin Sci Bull, 2012, 57: 4462-4471, doi: 10.1007/s11434-012-5361-2

Frozen soil is a special soil type that is widely distributed across the global land surface. Of the total land surface coverage, permafrost accounts for about $25 \%$; coupled with seasonal frozen soil it accounts for about $50 \%$. Frozen soil is one element in the cryosphere. Under the background of global change, its interaction with global climate has attracted increased attention [1-3]. The interaction between frozen soil and climate change has been studied. However, prior research mainly focused on the impact of climate

*Corresponding author (email: wby@ cams.cma.gov.cn) change on frozen soil [4,5]. There has been less research on the impact of frozen soil on regional climates, especially on China.

Land-atmosphere coupled modeling is an important tool for studying land-atmosphere interaction, and provides a means for quantitative research on the impacts of frozen soil changes on global and regional climates. In recent years, with the development of land surface models [6-9], progress has been made in frozen soil parameterization schemes [10-12], but there are still problems. Given the complexity of the water-heat balance process in frozen soil, it is still 
very difficult to reasonably parameterize thermal and hydraulic properties and the freeze-thaw process of this soil.

To determine water and ice contents of frozen soil, land surface models must fully solve the coupling state equation between soil temperature and soil water (solid, liquid and gaseous). Based on the soil water-heat coupling relation, 10 equations were established by Zhao et al. [13] and Jordan et al. [14]. Nevertheless, certain phase hypothesis relations are required to close the equations. Moreover, because of computational stability and iterative convergence problems, these equations cannot be applied to global land surface modeling of the large scale. Total water and total enthalpy of soil have been used by $\mathrm{Li}$ et al. $[15,16]$ as prognostic variables to solve the soil water-heat amount. Finally, the relation equation between soil matric potential and temperature below the freezing point was used to diagnose soil water and ice contents. Based on a reasonable simplification, the soil thermodynamic equilibrium and soil matric potential equations were used by Niu et al. [17] to assess supercooled soil water conception in the Community Land Model (CLM). In addition, supercooled soil water was also considered in the latest domestic research on frozen soil parameterization schemes $[18,19]$, basically similar to the Niu et al. scheme.

CLM is a coupled land surface model within the Community Atmospheric Model (CAM) of the U.S. National Center for Atmospheric Research (NCAR). It combines advantages of Biosphere-Atmosphere Transfer Scheme (BATS), Institute of Atmospheric Physics (IAP94), NCAR Land Surface Model (LSM) and other advanced land surface models, improves physical parameterization schemes, and adds hydrological, geo-biochemical and dynamic vegetation processes. It is one of the most widely-used land surface models in the world [20]. Atmospheric model CAM3.1 was coupled with CLM3.0 as a tool in this study. Ensuring conditions of energy-water balance between land and atmosphere and with reference to the frozen soil parameterization scheme of Niu et al. [17], the supercooled water process was introduced in CLM3.0 to change water and ice contents of frozen soil. Such ratio changes affect thermal and hydraulic properties of frozen soil, which is taken as a starting point for studying the impacts of frozen soil changes on the climate system. A small number of domestic and foreign works have focused on impacts of the frozen soil process on climate, using a coupled model. The main purpose of the vast majority of these was improvement of model simulation skills. The frozen soil process was added to NCAR LSM by Zhang et al. [21] and coupled with
NCAR CCM3, to improve simulation of the atmospheric model. The soil freeze-thaw process was added in CCM3 by Wang et al. [22], and it was found to improve summer rainfall simulation skills in China. The frozen soil process was integrated in the European Centre for Medium-Range Weather Forecasts (ECMWF) land surface model by Viterbo et al. [23], ameliorating the problem of colder winter surface temperatures. The soil freeze-thaw parameterization scheme was improved in CAM by Li et al. [24], which was found to have a major impact on simulation of the East Asian monsoon. The uniqueness of this study is its focus on the response of atmospheric circulation to land surface processes with or without supercooled soil water, i.e. essentially the response to changes in ice-water ratio of frozen soil. Such response reflects the sensitivity of the climate system to frozen soil changes. In the early stages of global frozen soil change, part of soil ice is converted to liquid water, leading to changes in ice-water ratio of frozen soil. Therefore, potential impacts of frozen soil degradation on future climate are also simulated to an extent here. Additionally, we also focused on impacts of this change on the East Asian monsoon and summer rainfall.

\section{Model and numerical experiment setup}

\subsection{Introduction to CAM}

CAM3.1 of NCAR was adopted, for the following reasons: (1) Both CAM and CLM are numerical models with full two-way coupling; and (2) CAM is an open model whose program is easily obtained, with greater portability and application. Compared with previous versions, from dynamic framework to physical processes, numerous improvements have been made to CAM3.1, giving better performance [20]. CAM is a global static spectrum model, whose dynamic framework has three options, i.e. Euler, finite-volume and semi-Lagrangian. Under normal circumstances, the Euler framework is the model default, with spectral resolutions T85, T63, T42 and T31. The $\sigma-p$ hybrid coordinate is used in the vertical direction, whereas terrain follows a $\sigma$ coordinate in the near-surface layer. A $\sigma-p$ transition coordinate is used in the middle, and a $p$ (pressure) coordinate in the upper layer. A total of 26 layers are used. The physical process of CAM includes radiation, cumulus convection and boundary layer schemes. Table 1 lists the main schemes used here. Compared with previous versions, many improvements and optimizations have been made in the CAM3.1 physical process [25].

Table 1 Main physical process schemes of CAM3.1

\begin{tabular}{cl}
\hline Radiation scheme & Cumulus convection scheme \\
\hline Short-wave radiation: Briegleb-Bruce scheme & Deep convention: Zhang-McFarlane scheme \\
Long-wave radiation: Collins et al. scheme & Shallow convention: Hack scheme \\
\hline
\end{tabular}




\subsection{Impact of unfrozen water process on CLM3.0}

Unfrozen soil water refers to an amount of liquid water in soil whose temperature is below the freezing point $\left(0^{\circ} \mathrm{C}\right)$ [26]. Owing to absorptive and capillary forces exerted by soil particles, water molecules are not immediately frozen when soil temperature is below the freezing point, and ice and water coexist within a certain temperature range.

In the treatment of soil liquid water freezing, simpler freezing conditions are used in CLM3.0. That is, when soil water content is greater than $0 \mathrm{~kg} \mathrm{~m}^{-3}$ and soil temperature less than $0^{\circ} \mathrm{C}$, soil liquid water is deemed entirely frozen. The unfrozen water process is not considered in this approach, which was improved by Niu et al. [17]. The improved method was adopted here, as shown by the following.

The equilibrium thermodynamic relation, based on soil matric potential and temperature, is shown below [27].

$$
\psi_{j}=10^{3} \cdot \frac{L_{f}\left(T_{j}-273.16\right)}{g T_{j}},
$$

where $\psi_{j}$ is soil matric potential, $T_{j}$ is soil temperature (below freezing point), $g$ is acceleration of gravity, and $L_{f}$ is water latent heat.

The Generalized Clapp-Hamberg relation [28] is obtained on the basis of massive field observations and tests of frozen soil, as shown below.

$$
\psi_{j}=\psi_{0}\left(\frac{\theta_{l}}{\theta_{s}}\right)^{-b}\left(1+c_{k} \theta_{i}\right)^{2},
$$

where $\psi_{j}$ is soil matric potential, $\psi_{0}$ is saturated soil matric potential, and $\theta_{l}$ and $\theta_{i}$ are water and ice volume contents, respectively, $\theta_{s}$ is the effective porosity of soil, $b$ is the Clapp coefficient, and $c_{k}$ is a constant.

The following is obtained:

$$
\theta_{l \max }=\theta_{s}\left[\frac{\times 10^{3} L_{f}\left(T_{j}-273.16\right)}{g \psi_{0} T_{j}}\right]^{\frac{-1}{b}} .
$$

The relation between soil temperature $T_{j}$ (below freezing point) and maximum volumetric water content (liquid water) $\theta_{l \max }$ is established in eq. (3). Using that equation, the new freezing condition becomes as follows: When soil volumetric water content is greater than $\theta_{l \max }$ and soil temperature is less than $0^{\circ} \mathrm{C}$, the excess part will be frozen. It is seen from eq. (3) that the maximum volumetric water content (below freezing point) is inversely proportional to soil temperature, but proportional to the effective soil porosity (soil property). Therefore, when soil temperature is close to the freezing critical point, the finer the soil particles and the greater the maximum water content.

When there are no changes to total precipitation, the essence of the new freezing condition proposed by Niu et al.
[17] is definition of the ice with volume content $\theta_{l \max }$ in the soil as supercooled soil water. Therefore, with introduction of this new freeze condition in CLM3.0, the simulated soil ice content is reduced, while increasing the water content. We used a set of meteorological and hydrological data spanning 18 years (1966-1983), from Valdai frozen soil observation station in the former Soviet Union, to validate the new freezing condition. It is seen from Figure 1 that the ice content $\left(\mathrm{kg} \mathrm{m}^{-2}\right)$ in shallow soil $(0-0.4 \mathrm{~m})$ is significantly reduced, while water content $\left(\mathrm{kg} \mathrm{m}^{-2}\right)$ increases. In Layer $4(0.12 \mathrm{~m})$ of the model, the 16-year average reduced ice content accounts for $19.1 \%$ of total water amount in this layer.

\subsection{Numerical experiment design and parameter setting}

Two sets of numerical experiments were conducted. CAM3.1 integration with no change was named CAM_CTRL, while CAM3.1 integration with supercooled soil water process was named CAM_NEW. Except for this difference, other configurations in CAM3.1 were the same. The Euler scheme was selected in the CAM3.1 dynamic framework, with spectral resolution T85. Initial fields of CAM3.1 and CLM3.0 were the global fields on September 1. These are gotten from the coupled models' control run which reaching equilibrium after multi-year integration. The start time of model integration was September 1, 1974. To more clearly highlight impacts of supercooled soil water on atmospheric circulation, without annihilation by ENSO and other strong external forcings, SST and sea ice boundary conditions of CAM3.1 were chosen as climatological mean values. Other forcings, such as carbon dioxide, aerosol, volcanic eruptions and sulfide, were selected as the model default values. There were two experimental integrations of 30 years. Taking into account the model equilibrium state requiring adjustment and adaptation periods, simulation results for the last five years were used for analysis.

\section{Result}

Model output data referenced 30-year monthly average data, on a non-uniform Gaussian grid of resolution about $1.4^{\circ} \times$ $1.4^{\circ}$. We selected integration data from the aforesaid five years, i.e. from September 1999 to September 2004. The spring average refers to the average of March, April and May, summer to that of June, July and August, autumn to that of September, October and November, and winter to that of December, January and February.

\subsection{Soil water}

As mentioned above, the essence of the new freezing condition in CLM3.0 is changing part of frozen soil ice into liquid water, leading to reduced ice content within shallow soil 
layers and increased water content (soil moisture). Figure 2 shows soil water and ice content differences between CAM_NEW and CAM_CTRL in CAM3.1 simulations, with or without the unfrozen water process (results for summer and autumn are not shown, because of an insignificant difference). The figure indicates that in Eurasian winter

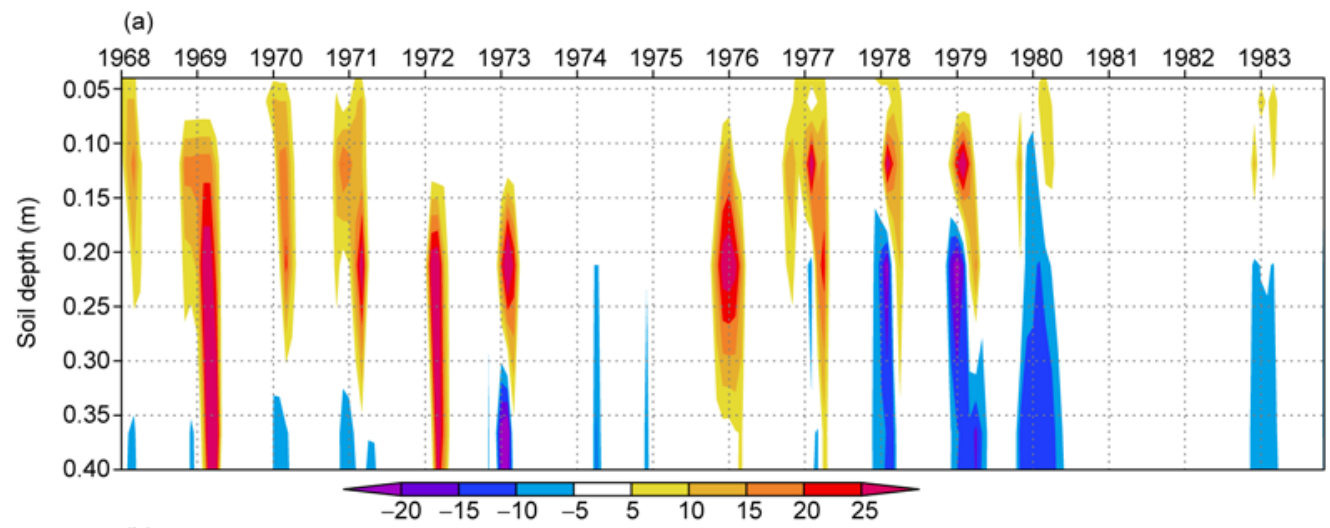

(b)

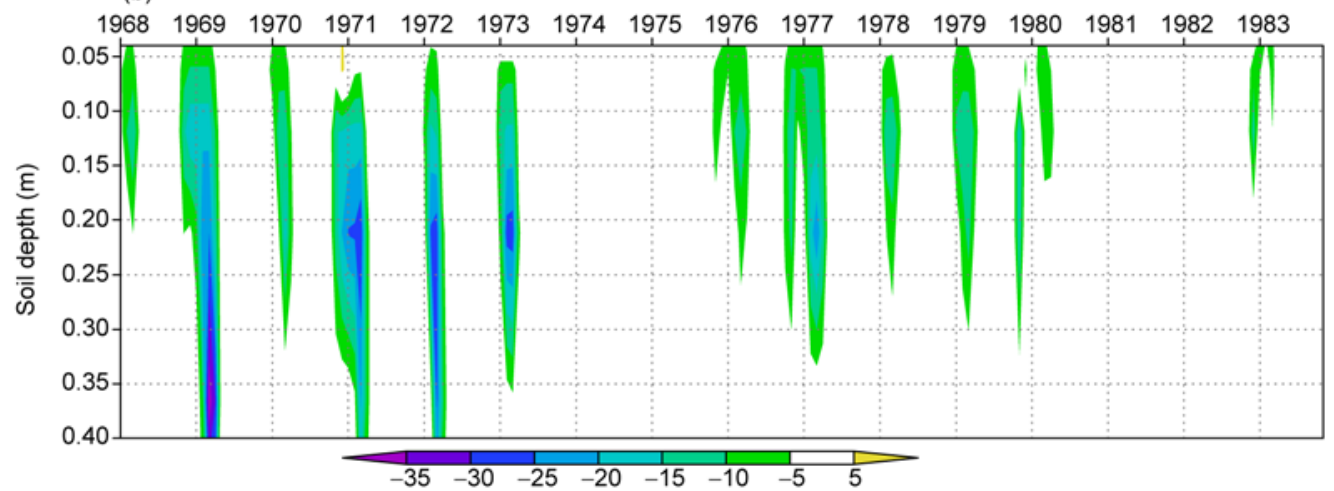

Figure 1 Time-depth cross-section of simulation differences (NEW-CTRL) in (a) water content (unit: $\mathrm{kg} \mathrm{m}^{-2}$ ), and (b) ice content (unit: $\mathrm{kg} \mathrm{m}^{-2}$ ) at Valdai Station from 1968 to 1983.
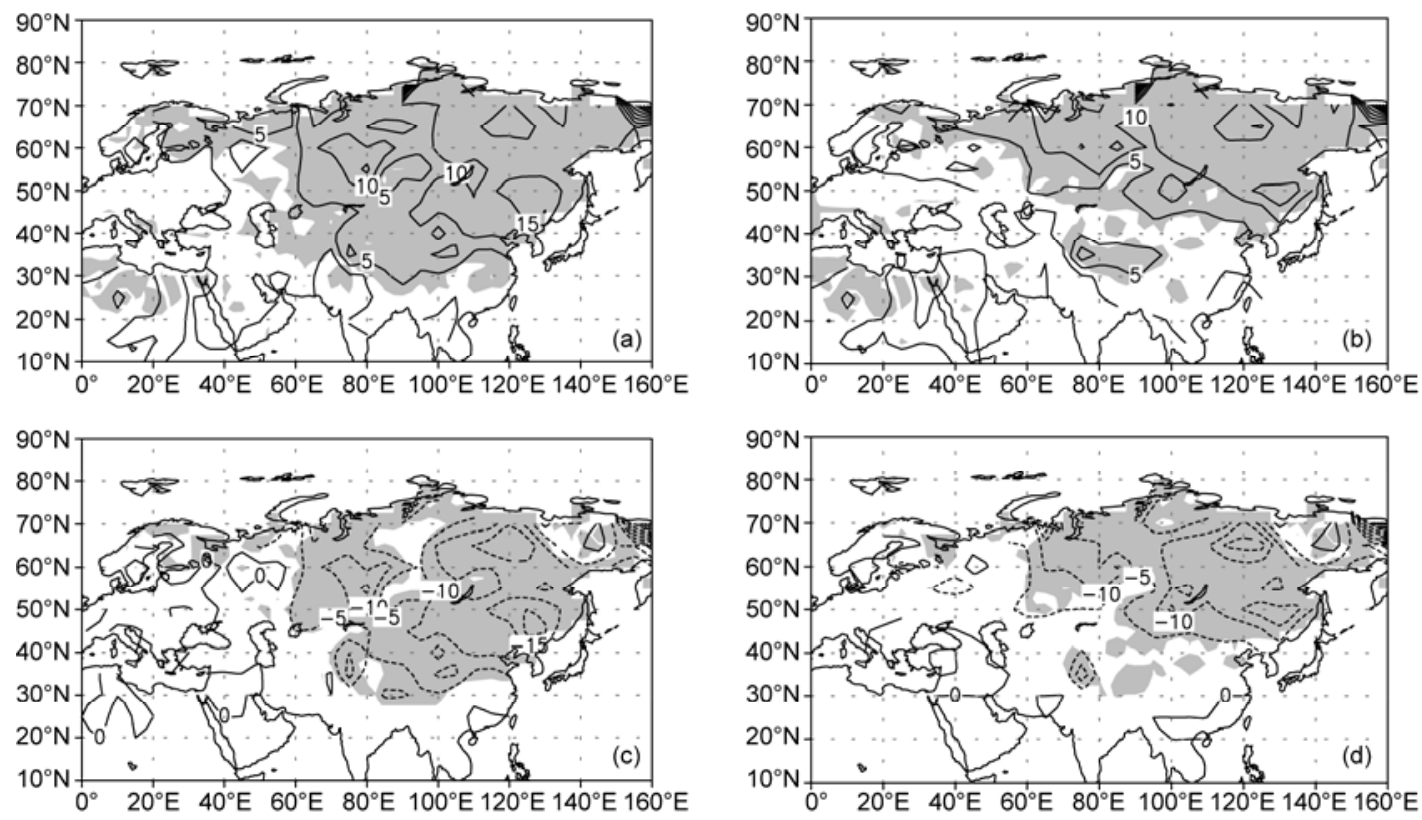

Figure 2 Differences in Eurasian winter ((a) and (c)), and spring ((b) and (d)) shallow soil water content (0.027-0.37 $\mathrm{m})\left(\mathrm{unit}\right.$ : $\left.\mathrm{kg} \mathrm{m}^{-2}\right)$ and ice content (unit: $\mathrm{kg} \mathrm{m}^{-2}$ ), between CAM_NEW and CAM_CTRL (NEW-CTRL). Shaded areas are statistically significant at the 95\% significance level according to Student's $t$-test. (a) and (b) indicate liquid water; (c) and (d) indicate soil ice. 
and spring, especially in the eastern part of mid-high latitudes, there is a large range of negative difference in ice content of shallow soil $(0.027-0.37 \mathrm{~m}$, i.e. the volumetric average of Layer 2 through 6 in CLM3.0), which passes the 95\% confidence level test in most areas. Correspondingly, there is a larger range of positive difference in water content. Spatial differences of water content and ice content basically correspond, but there are some slight differences. For example, during spring in Southwest China (including the Qinghai-Tibet Plateau), the difference range of water content does not match that of ice content because soil porosity changes with ice content in frozen soil, leading to changes in the water balance process of frozen soil. Additionally, after the supercooled soil water process is added in the coupled model, atmospheric precipitation also changes.

\subsection{Ground surface temperature}

Ground surface temperature is an important variable in land surface models and as a boundary condition of atmospheric models. This temperature is mainly affected by atmospheric radiation and other external forcings. In CLM3.0, this temperature is the soil temperature of the first layer $(0.007 \mathrm{~m})$. Figure 3 shows the four seasonal differences of Eurasian ground surface temperature, between CAM_NEW and CAM_CTRL. The figure shows that the winter Eurasian ground surface temperature is significantly different, passing the $90 \%$ confidence level test in most areas (shaded in the figure). In winter, there is a slightly significant positive difference centered on Lake Baikal, Siberia. There is a significant negative difference in northern Europe, different from the simulations of $\mathrm{Li}$ et al. [24]. Driven by the ob- served atmospheric forcing, the impact of the supercooled soil water process on surface temperature simulated in CLM3.0 appears as cooling. However, in the global coupled run, there is an interaction between atmosphere and land. Thermal and hydraulic changes in frozen soil have an impact on atmospheric circulation, which changes near-surface radiation. Therefore, there cannot be uniform spatial cooling of surface temperature. The supercooled soil water process occurs mainly in winter. Consequently, surface temperatures in the other three seasons changed, but these changes did not pass the significance test.

\subsection{Soil temperature}

In soil, latent heat released (absorbed) by the water freezing (thawing) process has a great impact on soil temperature. After adding the supercooled soil water process in CLM3.0, ice content is reduced and releases less latent heat than before, so the simulated soil temperature decreases. Figure 4 shows the four seasonal differences of Eurasian shallow soil layer temperature $(0.027-0.21 \mathrm{~m}$, i.e. the volumetric average from Layer 2 through 5 in CLM3.0) between CAM NEW and CAM_CTRL. Differences are more significant in winter and spring, with shaded areas passing the $95 \%$ level in the confidence test. Comparing Figures 3 and 4, differences in ground surface temperature and shallow soil temperature are more significant in winter, and there are two more significant difference centers (i.e. positive and negative difference centers) in Eurasian surface temperature. There is a positive difference in northwest Eurasia with central value exceeding $-4^{\circ} \mathrm{C}$, while there is a negative difference in the east with center value less than $2^{\circ} \mathrm{C}$. However,
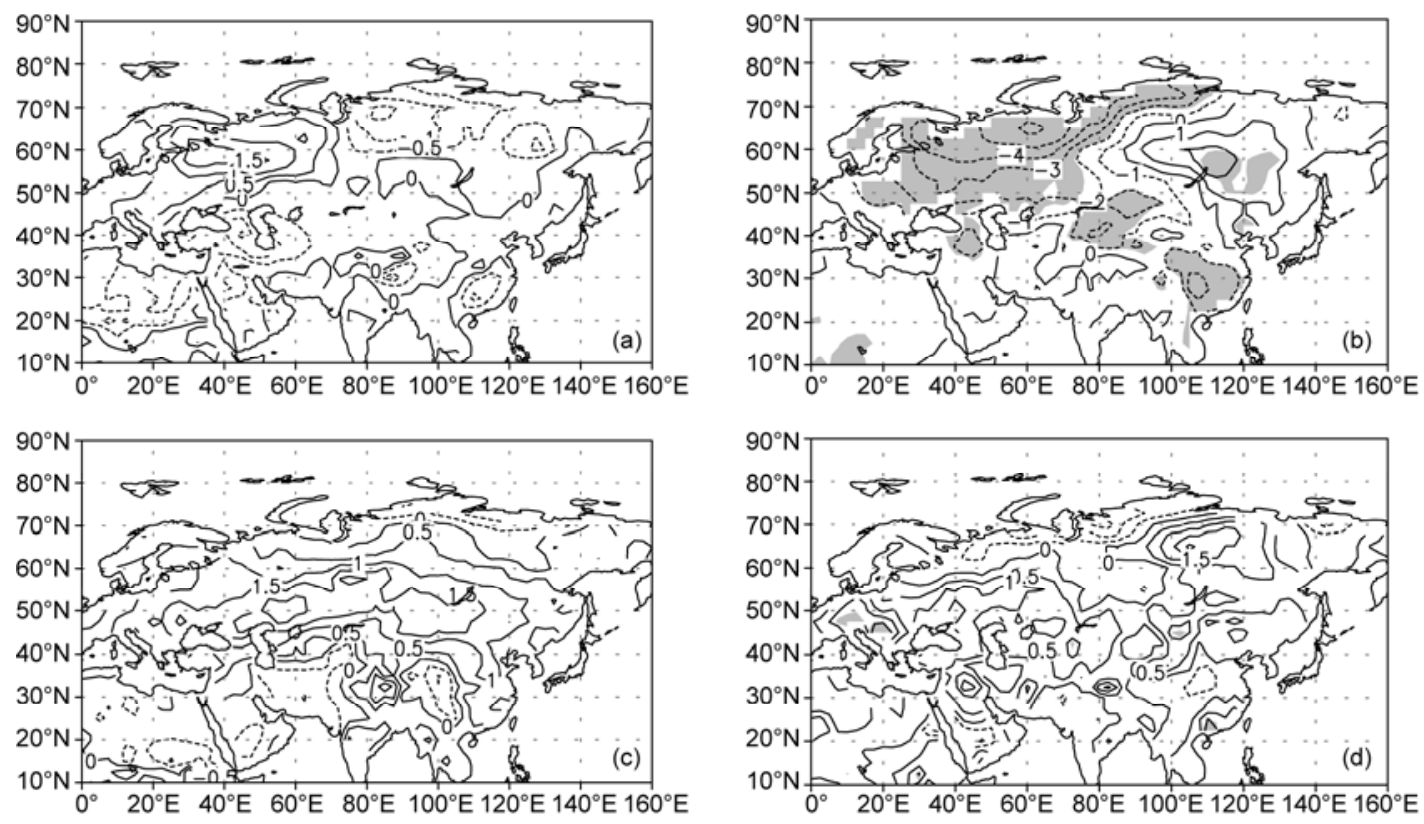

Figure 3 Seasonal differences in Eurasian ground surface temperature between CAM_NEW and CAM_CTRL (unit: ${ }^{\circ} \mathrm{C}$ ) (NEW-CTRL): (a) autumn; (b) winter; (c) spring; (d) summer. Shaded areas indicate statistical significance at the $90 \%$ level according to Student's $t$-test. 
all Eurasian soil temperatures show negative differences. The supercooled soil water process influences surface temperature, but because of the thinner first soil layer in CLM3.0, supercooled soil water content is less. Therefore, released and absorbed latent heat is not dominant compared with downward ground heat flux. Therefore, surface temperature is mainly affected by atmospheric radiation, and thus the positive and negative difference centers in Eurasia. However, soil temperature is different. For the second layer of CLM3.0, soil thickness is increased, and supercooled soil water is greatly increased over the first layer. The impacts of latent heat release and absorption on temperature begin to dominate, so that the distribution of difference between CAM_CTRL and CAM_NEW is only negative in Figure 4. The difference in volumetric water content of east Eurasia is slightly greater than that of the west (Figure 2), resulting in a greater negative difference in the soil temperature of the east. Because there is almost no supercooled soil water in autumn and summer, ground surface temperature and soil temperature differences are not significant.

\subsection{Upper-lower circulation}

Do significant changes in frozen soil influence atmospheric circulations? In principle, changes in surface temperature and soil moisture of frozen soil significantly affect upward sensible and latent heat fluxes [29,30], which will lead to atmospheric circulation anomalies. Figure 5 shows differences in upper $(500 \mathrm{hPa})$ and lower (sea level) circulations between CAM_NEW and CAM_CTRL. In January, there are more significant sea-level Aleutian Low anomalies. The center of the North Pacific Aleutian Low is usually around $180^{\circ}$ and $45^{\circ} \mathrm{N}$ during January [31]. Figure 5(a) indicates negative pressure anomalies centered near the aforementioned location, with positive pressure anomalies to the east and west. This suggests that the low pressure is being strengthened. At $500 \mathrm{hPa}$, there are significant positive anomalies near $120^{\circ} \mathrm{E}$ and $50^{\circ} \mathrm{N}$ at mid-latitudes on the East Asian coast. There are significant negative anomalies near the west side of the Ural Mountains, indicating a weakened East Asian trough and Ural blocking high. Such a configuration of upper and lower circulations can explain well the abnormal distribution of ground surface temperature during the Eurasian winter (Figure 4(b)). In July, it is evident from the sea level pressure field that there are significant negative anomalies around the Aleutian Islands. At $500 \mathrm{hPa}$, there are positive anomalies of geopotential height adjacent to the Sea of Japan, with significant negative anomalies at the latitude of China's eastern coastal areas.

\subsection{East Asian $850 \mathrm{hPa}$ wind field}

The monsoon is a significant characteristic of East Asian climate. To reveal the East Asian monsoon anomaly intuitively, differences in January and July $850 \mathrm{hPa}$ wind fields between CAM_NEW and CAM_CTRL are shown (Figure 6). In January, corresponding to a weakened East Asian Trough (Figure 5(c)), there are significant southeast wind anomalies in East China, indicating a greatly weakened East Asian winter monsoon. In July, the wind field anomaly is more complex. In central China, to the west of $110^{\circ} \mathrm{E}$ from $30^{\circ}-40^{\circ} \mathrm{N}$, northerly wind anomalies are more significant. In China's eastern coastal areas to the east of $110^{\circ} \mathrm{E}$, southwest wind anomalies are significant, corresponding to
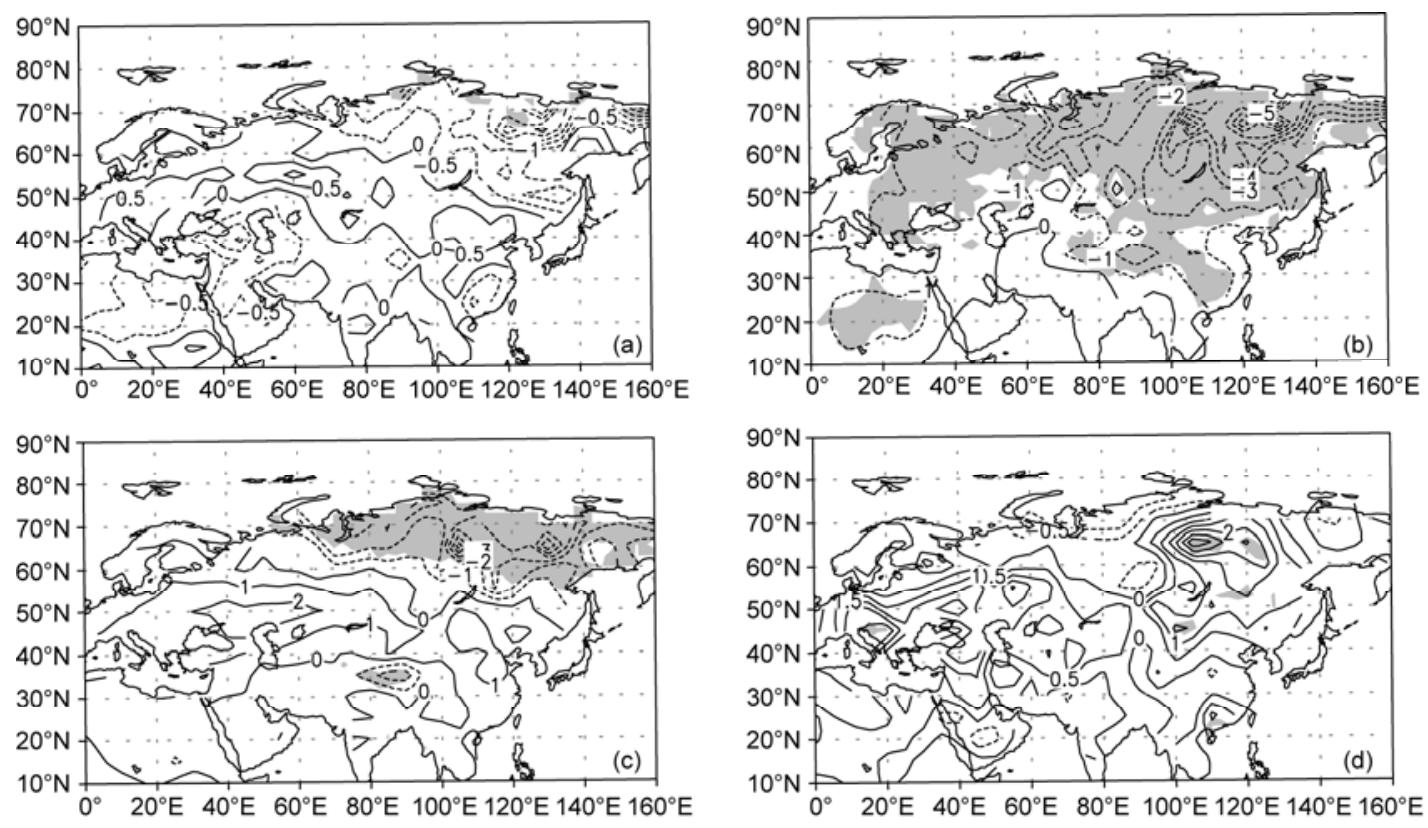

Figure 4 Same as in Figure 3, but for shallow soil temperature (unit: ${ }^{\circ} \mathrm{C}$ ). Shaded areas represent statistical significance at the $95 \%$ level according to Student's $t$-test. 

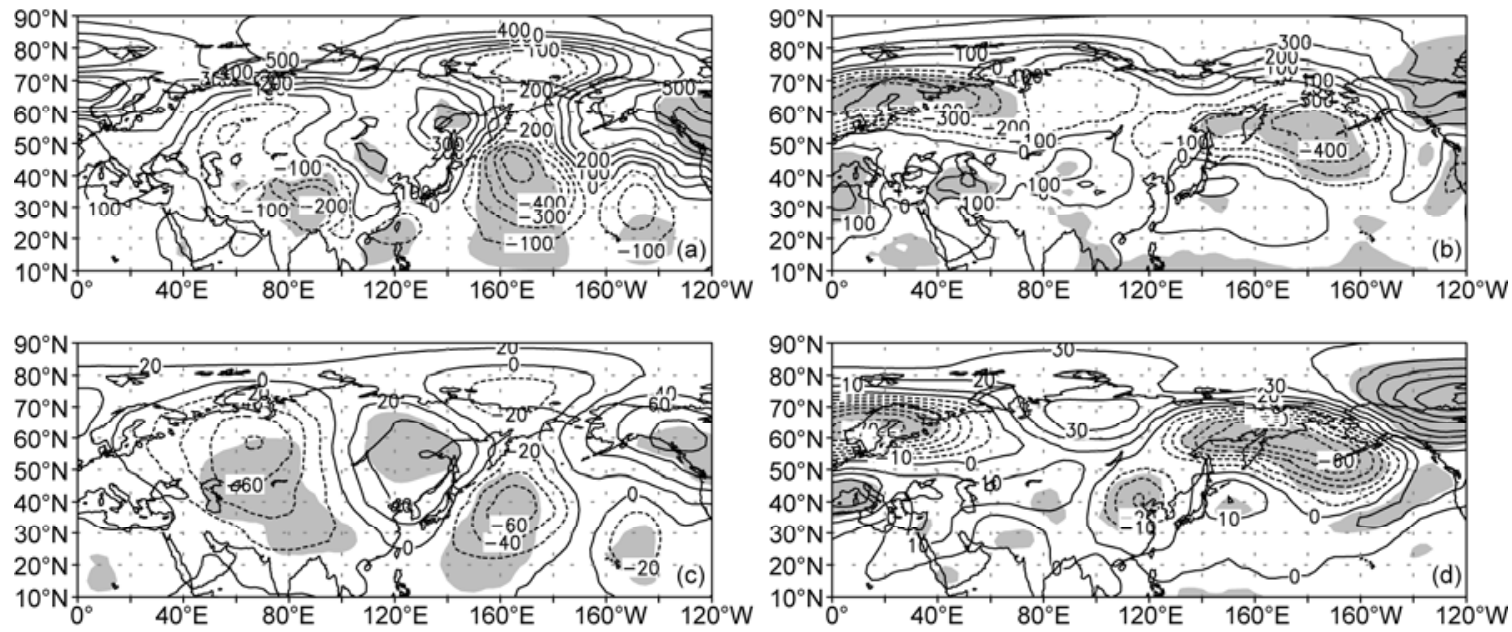

Figure 5 Differences in Eurasian and North Pacific January ((a) and (c)), and July ((b) and (d)) sea level pressure (unit: Pa) and 500 hPa geopotential height (unit: gpm), between CAM_NEW and CAM_CTRL (NEW-CTRL). Shaded areas represent statistical significance at the 98\% level according to Student's $t$-test. (a) and (b) indicate sea level pressure; (c) and (d) show geopotential height at $500 \mathrm{hPa}$.
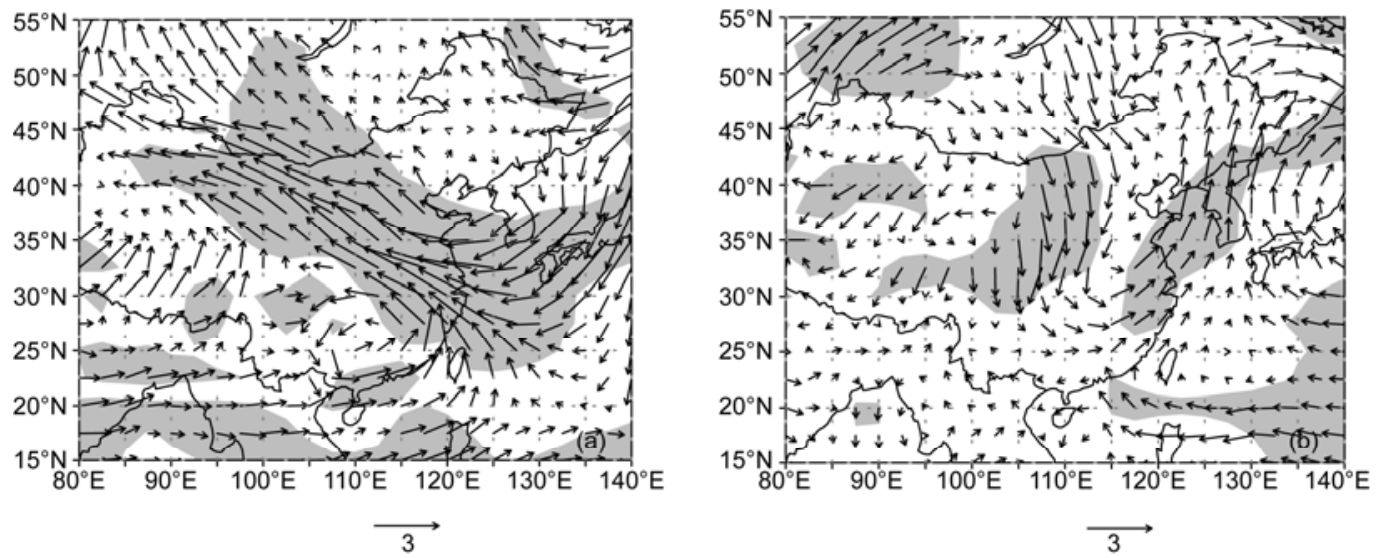

Figure 6 Differences in East Asian January (a), and July (b) $850 \mathrm{hPa}$ wind field between CAM_NEW and CAM_CTRL (NEW-CTRL). Shaded areas represent statistical significance at the $95 \%$ level according to Student's $t$-test.

$500 \mathrm{hPa}$ height field anomalies (Figure 5(d)). There are cyclonic anomalies in northeast China, and anticyclonic anomalies in the Sea of Japan. Thus, significant southerly wind anomalies form between the two regions, i.e. the summer monsoon is greatly enhanced in China's eastern coastal areas.

\subsection{East Asian summer rainfall}

Precipitation is an important meteorological element, and East Asian precipitation has a major impact on climate change in China. Figure 7 shows differences in East Asian summer precipitation between CAM_NEW and CAM_CTRL. This figure reveals that from west to east along $30^{\circ} \mathrm{N}$, there are two positive anomaly centers passing the significance test; one is on the southern Qinghai-Tibet Plateau, and the other in the central Yangtze River basin. In addition, there is a significant positive anomaly center in northeast China. This

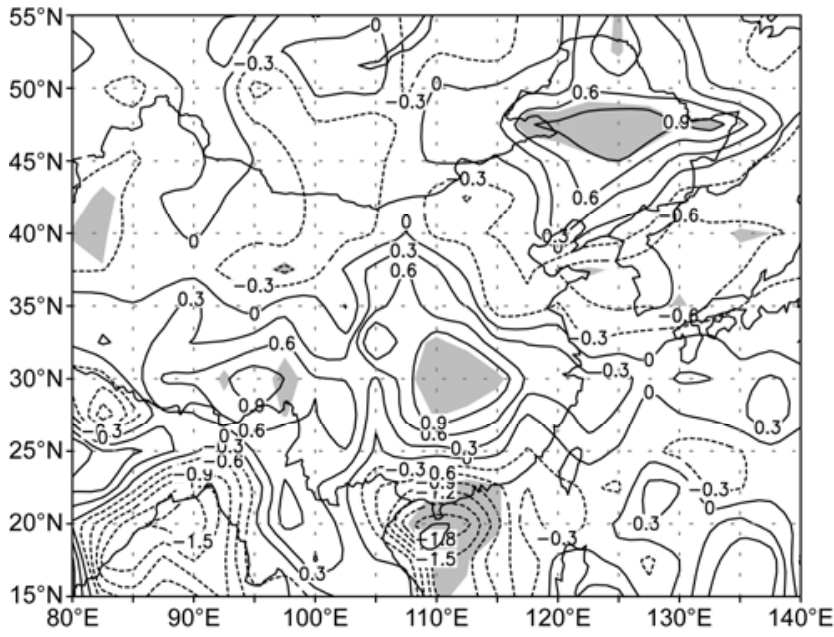

Figure 7 Differences in East Asian summer precipitation between CAM_ NEW and CAM_CTRL (unit: $\mathrm{mm} / \mathrm{d}$ ) (NEW-CTRL). Shaded areas represent statistical significance at the $95 \%$ level according to Student's $t$-test. 
represents an increase of summer precipitation in these areas. Meanwhile, there is a significant negative precipitation anomaly center in south China and Hainan Island. In addition, there are a number of negative anomaly centers from west to east along $40^{\circ} \mathrm{N}$, where precipitation in the Tarim and Qaidam basins are notably reduced. Precipitation in Hohhot, Inner Mongolia and central Hebei are reduced, but insignificantly. East Asian summer precipitation is principally modulated by the East Asian summer monsoon. Corresponding to $850 \mathrm{hPa}$ wind field anomalies (Figure 5(b)), there are northerly wind anomalies in the central region west of $110^{\circ} \mathrm{E}$, which converge with a Pacific southerly wind from $25^{\circ}-30^{\circ} \mathrm{N}$. This produces excessively high precipitation in the region. In northeast China, because of the greatly strengthened summer monsoon of China's eastern coastal areas, Pacific warm-humid air converges with northern cold air over northeast China, generating increased precipitation there.

To further investigate reasons for the precipitation anomalies, Figure 8 shows a latitude-height cross-section of zonal average $\left(105^{\circ}-115^{\circ} \mathrm{E}\right)$ difference of vertical velocity, tem- perature and geopotential height, between CAM_NEW and CAM_CTRL. Figure 8(a) indicates that near $30^{\circ} \mathrm{N}$, there is a significant upward vertical velocity anomaly (downward is positive, $\mathrm{Pa} \mathrm{s}^{-1}$ ), signifying enhanced vertical upward motion of the air mass close to this latitude. Accordingly, there is a sinking air mass on both sides of $30^{\circ} \mathrm{N}$. Regarding the vertical distribution of temperature anomalies, $30^{\circ} \mathrm{N}$ is at the junction of warm and cold anomalies, with significant upward motion. This increases precipitation anomalies in the middle Yangtze River basin. There are warm anomalies on the south side, but these are associated with enhanced descent, so precipitation is reduced in north China. There are cold anomalies on the north side (Figure 8(b)), associated with significantly enhanced descending motion, so precipitation in north China is also abnormally diminished. Further analysis reveals a significant warm center on top of the northern downdraft, which indicates that the converged warm-humid air rising near $30^{\circ} \mathrm{N}$ releases condensation latent heat at the upper level. The vertical distribution of geopotential height anomalies further validates the aforementioned circulation anomalies. The enhanced vertical
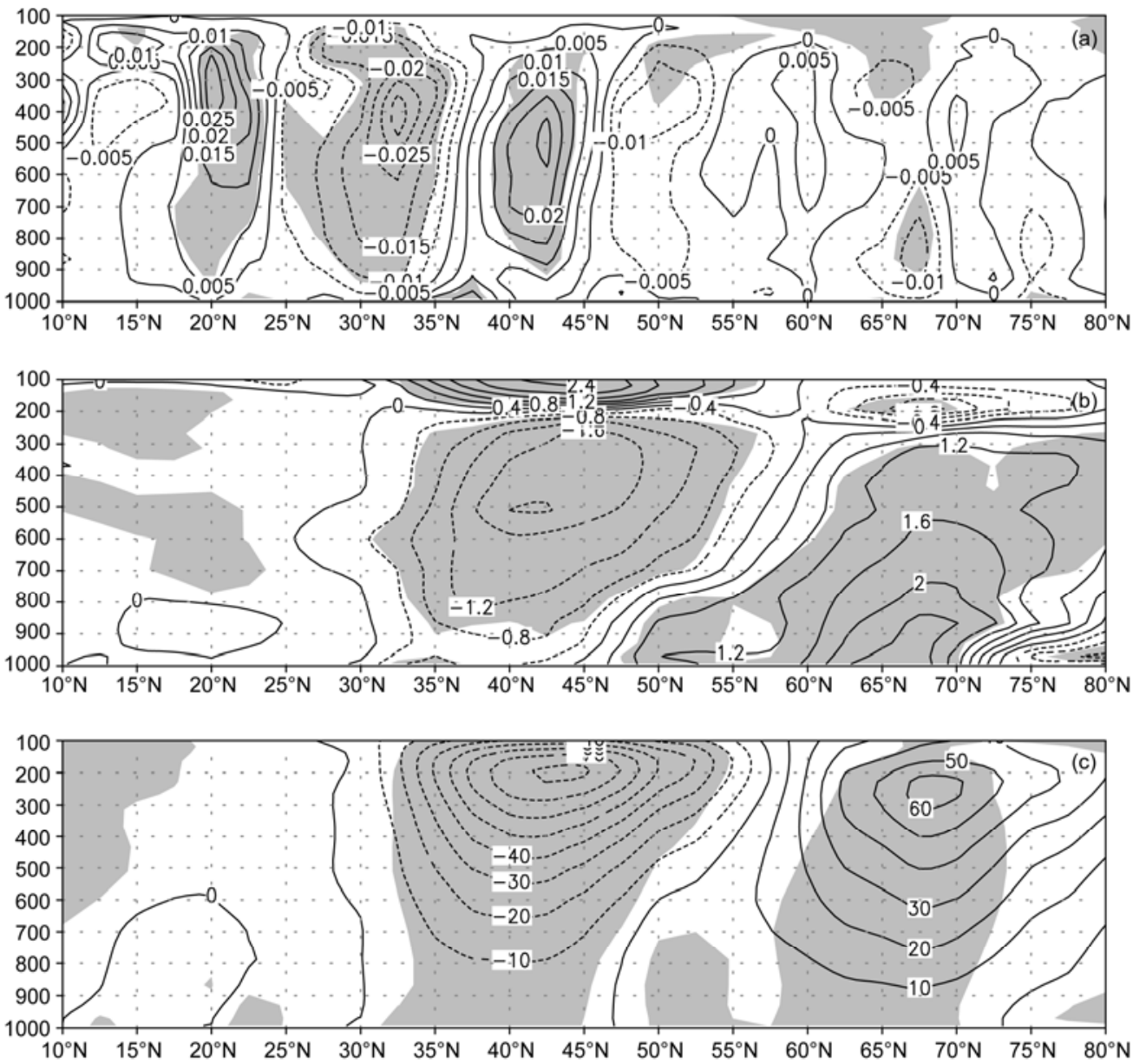

Figure 8 Differences along latitude-height cross-section $105^{\circ}-115^{\circ} \mathrm{E}$ of zonal-average (a) vertical velocity (unit: $\mathrm{Pa} \mathrm{s} \mathrm{s}^{-1}$ ), (b) temperature (unit: ${ }^{\circ} \mathrm{C}$ ), and (c) geopotential height (unit: gpm) between CAM_NEW and CAM_CTRL. Shaded areas represent statistical significance at the 95\% level according to Student's $t$-test. 
upward motion near $30^{\circ} \mathrm{N}$ converges at the lower level, and diverges at the upper level towards north and south. Therefore, there are significant negative anomaly centers of geopotential height at the $200 \mathrm{hPa}$ junction of warm and cold air on the north side. Because of the temperature field configuration, although the south-branch upper flow diverges and descends, there is no significant height field anomaly.

\section{Discussions and conclusions}

Frozen soil is widely distributed in the world, with a great impact globally and in East Asia. In this study, under the premise of land-atmosphere energy and water conservation, the supercooled soil water process was added to CAM3.1 for changing the soil ice and water ratio in the model. Through comparison of two sets of numerical experiments, the following conclusions were reached:

(1) The introduction of the supercooled soil water process in CAM3.1 substantially changes the ice and water ratio of frozen soil, thereby altering its thermal and hydraulic conditions. Such change has a greater impact on winter ground surface temperature and soil temperature, for which there were positive and negative anomaly centers of ground surface temperature in Eurasia.

(2) Eurasian (including East Asia) climate is more sensitive to changes in frozen soil. In January, the sea-level Aleutian Low is strengthened, while the $500 \mathrm{hPa}$ Ural blocking high and East Asian trough are weakened. In July, there were negative anomalies of sea level pressure near the Aleutian Islands. There were significant $500 \mathrm{hPa}$ geopotential height anomalies adjacent to the Sea of Japan, but significant negative anomalies at the same latitude in China's eastern coastal areas.

(3) The $850 \mathrm{hPa}$ wind field was also significantly affected. In January, owing to a weakened East Asian Trough, there were significant southeast winds from middle and lower Yangtze River basin areas to northwest China. The southerly wind component of the winter monsoon was greatly enhanced, indicating a significantly weakened East Asian winter monsoon. In July, there were significant southwest wind anomalies in China's eastern coastal areas, to the east of $110^{\circ} \mathrm{E}$. However, there were cyclonic anomalies in the $500 \mathrm{hPa}$ height field over northeast China, and anticyclonic anomalies over the Sea of Japan. Thus, significant southerly wind anomalies formed in the two regions, proving that the summer monsoon greatly strengthened in China's eastern coastal areas.

(4) Further analysis revealed that owing to significant upward anomalies of vertical velocity from west to east along $30^{\circ} \mathrm{N}$, warm and cold air converged and produced positive precipitation anomalies in the central Yangtze River basin. To the south, from $25^{\circ}$ to $20^{\circ} \mathrm{N}$, although water vapor transport is sufficient in south China, air descent is strong and unable to form much precipitation. To the north, between $40^{\circ}$ and $45^{\circ} \mathrm{N}$, air descent is also dominant, so regional precipitation is also reduced. However, in China's northeast coastal areas, because of an enhanced summer monsoon, Pacific warm-humid air flow converges with cold air in those areas, increasing regional precipitation.

In conclusion, given the simulation results from the coupled model, the Eurasian climate system is sensitive to frozen soil changes. Such changes cause significant ground surface temperature anomalies, leading in turn to sensible heat and latent heat flux anomalies. This ultimately results in anomalies of upper and lower circulations and precipitation. This study was based only on model simulation, which requires observational data for validation. The impact of cryospheric changes (including frozen soil) on climate is worthy of further research.

This work was supported by the National Basic Research Program of China (2007CB411505), the Youth Foundation of NSFC (40905048), and the Basic Scientific Special Project "Climate system model” of Chinese Academy of Meteorological Science (2008Z001 and 2010Z003).

1 Zhang T J, Barry R G, Knowles K, et al. Statistics and characteristics of frozen soil and ground ice distribution in the Northern Hemisphere. Pol Geogr, 1999, 23: 147-169

2 Wang S W, Gong D Y. China Western Environmental Characteristics and Evolution (in Chinese). Beijing: Science Press, 2002. 1-248

3 Qin D H, Ding Y J. Cryospheric changes and their impacts: Present, trends and key issues (in Chinese). Adv Clim Change Res, 2009, 54: 187-194

4 Li X, Cheng G D. Response model of high-latitude permafrost to global change (in Chinese). Sci China Ser D-Earth Sci, 1999, 29: 185-192

5 Jin H J, Li S X, Wang S L, et al. Impacts of climatic change on permafrost and cold region environments in China (in Chinese). Acta Geogr Sin, 2002, 55: 151-173

6 Dai Y J, Zeng X B, Dickinson R E, et al. The common land model (CLM). Bull of Amer Meter Soc, 2003, 84: 1013-1023

7 Yang Z L, Dickinson R E. Description of the Biosphere-Atmosphere Transfer Scheme (BATS) for the soil moisture workshop and evaluation of its performance. Glob Planet Change, 1996, 13: 117134

8 Sellers P J, Coauthors. A revised land surface parameterization (SiB2) for atmospheric GCMs. Part I: Model formulation. J Clim, 1996, 9: 676-705

9 Xin Y F, Bian L G, Zhang X H. Research on the application of CoLM model in northwest arid areas and Qinghai-Tibet Plateau (in Chinese). Plateau Meteorol, 2006, 26: 568-574

10 Wang C H, Dong W J, Wei Z G. The development of study on the soil freezing-thaw process in land surface model (in Chinese). Adv Earth Sci, 2002, 17: 44-52

11 Gao Z Q, Chae N, Kim J, et al. Modeling of surface energy partitioning, surface temperature and soil wetness in the Tibetan prairie using the Simple Biosphere Model 2 (SiB2). J Geophys Res, 2004, 109: D06102

12 Zhang Y, LÜ S H. Development and validation of a simple f rozen soil parameterization scheme used for climate model. Adv Atmos Sci, 2002, 19: 513-527

13 Zhao L, Cray D M, Male D H. Numerical analysis of simultaneous heat and water transfer during infiltration into frozen soil. J Hydrol, 1997, 200: 345-363

14 Jordan R. A one dimensional temperature model for a snow coverTechnical Documentation for THERM.89. US. Army Corps of Engineers, Cold Regions Research and Engineering Laboratory, Special Report 91-16, 1991 
15 Li Q, Sun S F. Research on the development and improvement of general water-heat transfer coupling model (in Chinese). Sci China Ser D-Earth Sci, 2007, 37: 1522-1535

16 Li Q, Sun S F, Xue Y K. analyses and development of a hierarchy of frozen soil models for cold region study. J Geophys Res, 2010, 115: D03107

17 Niu G Y, Yang Z L. Effects of frozen soil on snowmelt runoff and soil water storage at a continental scale. J Hydrometeorol, 2006, 7: 937-952

18 Xia K, Luo Y, Li W P. Simulation of freezing and melting of soil on northeast Tibetan Plateau. Chin Sci Bull, 2011, 56: 2145-2155

19 Li Z K, Wu B Y, Zhu W J, et al. Improvement and validation of the frozen soil parameterization scheme used in NCAR CLM3.0 model (in Chinese). Clim Environ Res, 2011, 16: 137-148

20 Collins W D, Rasch P J. The formulation and atmospheric simulation of the Community Atmosphere Model Version3 (CAM3). J Clim, 2006, 19: 2144-2161

21 Zhang Y, Song M H, LÜ S H, et al. Frozen soil parameterization scheme coupled with mesoscale model (in Chinese). J Glaciol Geocryol, 2003, 25: 541-546

22 Wang $\mathrm{C} \mathrm{H}$, Cheng G D, Deng A J, et al. Numerical simulation on climate effects of freezing-thawing processes using CCM3. Sci Cold Arid Reg, 2008, Initial Issue: 0068-0079

23 Viterbo P, Beljaars A, Mahfouf J F, et al. The representation of soil moisture freezing and its impact on the stable boundary layer. Quart J Roy Meteor Soc, 1999, 125: 2401-2426
$24 \mathrm{Li} \mathrm{Z} \mathrm{K,} \mathrm{Zhu} \mathrm{W} \mathrm{J,} \mathrm{Wu} \mathrm{B} \mathrm{Y.} \mathrm{Impact} \mathrm{of} \mathrm{improved} \mathrm{soil} \mathrm{freezing} \mathrm{process}$ on climate in East Asia using NCAR CAM model (in Chinese). Chin J Atmo Sci, 2011, 35: 683-693

25 Collins W D, Rasch P J. Description of the NCAR Community Atmosphere Model (CAM 3.0), Technical Report NCAR/TN-464+ STR, National Center for Atmospheric Research, Boulder, Colorado, 2004, 210

26 Xu X Z, Wang J C, Zhang L X. Frozen Soil Physics (in Chinese). Beijing: Science Press, 2001

27 Fuchs M, Campbell G S, Papendick R I. An analysis of sensible and latent heat flow in a partially frozen unsaturated soil. Soil Sci Soc, 1978, 42: 379-385

28 Clapp B J, Hornberger G M. Empirical equations for some soil hydraulic properties. Water Resour Res, 1978, 14: 601-604

29 Guo D L, Yang M X, Wang H J. Sensible and latent heat flux response to diurnal variation in soil surface temperature and moisture under different freeze/thaw soil conditions in the seasonal frozen soil region of the central Tibetan Plateau. Environ Earth Sci, 2011, 63: 97-107

30 Guo D L, Yang M X, Wang H J. Characteristics of land surface heat and water exchange under different soil freeze/thaw conditions over the central Tibetan Plateau. Hydrol Process, 2011, 25: 2531-2541

31 Li J P. Atlas of Climate of Global Atmospheric Circulation, I Climatological Mean State (in Chinese). Beijing: China Meteorological Press, 2001

Open Access This article is distributed under the terms of the Creative Commons Attribution License which permits any use, distribution, and reproduction in any medium, provided the original author(s) and source are credited. 